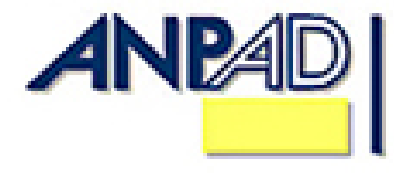

Disponível em

http://www.anpad.org.br/rac

RAC, Rio de Janeiro, v. 17, n. 1, art. 3,

pp. 42-63, Jan./Fev. 2013

$($ oc) EY-No

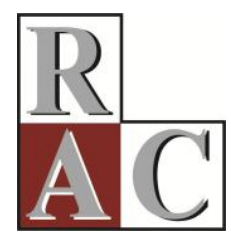

\title{
Gestão de Ativos de Propriedade Intelectual: um Estudo sobre as Práticas da Braskem S.A.
}

\author{
Managing Intellectual Property Assets: a Study on Braskem S.A. Practices
}

Elisabeth Loiola *

E-mail: beteloiola@oi.com.br Universidade Federal da Bahia - EA/UFBA Salvador, BA, Brasil.

Tatiane Mascarenhas E-mail: tatymasca@gmail.com Instituto Euvaldo Lodi - IEL/BA

Salvador, BA, Brasil.

\footnotetext{
* Endereço: Elisabeth Loiola

Rua Rodrigo Argolo, 293/501, Rio Vermelho, Salvador, BA, 41940-220.
}

Artigo recebido em 04.12.2011. Última versão recebida em 09.10.2012. Aprovado em 14.11.2012. 


\title{
Resumo
}

Este estudo de caso objetiva identificar o nível de alinhamento entre as práticas de gestão de ativos de Propriedade Intelectual (PI) da Braskem S.A. e o postulado pela literatura em termos de orientação estratégica. Estudos focados em sistemas de gestão de PI das empresas não foram localizados em busca bibliográfica, predominando aqueles com foco em países, regiões e setores e uso de abordagens econômicas e dados secundários. Argumenta-se que a gestão de ativos de propriedade intelectual pode agregar valor ao negócio se alinhada à estratégia competitiva das empresas, o que dirige o foco da análise à gestão de PI em empresas, nas dimensões operacional e estratégica, tomando-se como referências as estratégias competitivas. Foram realizadas entrevistas com informantes-chave, análise documental e de bases de dados de PI. Verificou-se que não há políticas formalmente dedicadas à gestão de PI, embora existam algumas diretrizes e normas de orientação das ações. Há uma coordenação de PI no setor de Inovação, em Triunfo (RS), já as atividades estão descentralizadas nos setores de tecnologia, de marketing e assessoria jurídica. Ativos de PI não são valorados. Práticas de gestão de PI estão alinhadas à estratégia empresarial e sofrem influências da estrutura de mercado, corroborando apenas parcialmente indicações da literatura revisada.

Palavras-chave: propriedade intelectual; tipos de propriedade intelectual; gestão estratégica de propriedade intelectual; petroquímica; estudo de caso.

\begin{abstract}
The objective of this case study is to identify the level of similarity between Intellectual Property Management (IPM) practices by Braskem S.A and the practices suggested by the literature in terms of strategic orientation. There is a lack of studies on IPM company practices, as studies instead focus primarily on countries, regions and sectors, using economic approaches and secondary data. We argue that IP management (IPM) can aggregate value to the business if it is aligned with firms' competitive strategies. This focuses the discussion on the operational and strategic dimensions of IPM in particular companies, taking their competitive strategies as references. Interviews with key-informers, document and IPM database analyses were carried out. We verified that there are no formally adopted policies for IPM, however a few guidelines and norms do exist. Structures dedicated to IPM are geographically centralized in Triunfo (RS), while activities are decentralized into the technology, marketing and legal advice sectors. Intellectual property asset values are not calculated. Braskem S.A. IPM practices are aligned with its business strategy and are influenced by its market structure, only partially matching the recommendations found in the literature review.
\end{abstract}

Key words: intellectual property management; kinds of intellectual property; strategic intellectual property management; petrochemical industry; case study. 


\section{Introdução}

Apesar do crescente uso de institutos de Propriedade Intelectual (PI), há uma grande polêmica sobre sua efetividade, seja para empresas, seja para países. Alguns estudiosos (e.g. Buainain \& Carvalho, 2000; Thumm, 2002) consideram que patentes viabilizam a apropriação econômica do esforço de inovação e de diferenciação, determinando, em última análise, decisões de investimento das empresas. Outros (e.g. Herscovici, 2007; Lerner, 2009) dizem que estudos empíricos evidenciam que o número de patentes registradas não está positivamente correlacionado ao progresso técnico, sendo que efeitos mais fracos estão nos países em desenvolvimento (Lerner, 2009), enquanto novo grupo (e.g. Candelin-Palmqvist, Sandberg, \& Mylly, 2012; Hanel, 2006; Thumm, 2002) ressalta que o uso de PI varia entre grupos de indústrias e tipos de empresas, mostrando-se mais difundido entre as indústrias química, farmacêutica, de biotecnologia, de alimentos, têxtil, metalomecânica e de produtos de metal, grandes empresas e multinacionais.

Em contexto de tendência ao crescimento de pesquisas sobre outros institutos de PI, verifica-se ainda grande concentração de estudos sobre patentes, patenteabilidade e de ampliação da aplicação de patentes a novos artefatos, como softwares, sobretudo no mundo anglo-saxônico. Pesquisadores da área de PI estão baseados, primordialmente, na Europa e nos Estados Unidos, enquanto os trabalhos utilizam muito frequentemente dados secundários, de nível macro. No caso de dados primários, o enfoque quantitativo é o principal (Candelin-Palmqvist et al., 2012).

Preocupações relativas à PI deixaram de ser de domínio exclusivo dos setores Jurídicos das empresas, passando a integrar a agenda da alta direção em muitas indústrias. Apesar dessas mudanças, estudos focando a gestão de PI (organização, tamanho, recursos humanos) são menos frequentes do que aqueles dirigidos para sua utilização e efetividade (Hanel, 2006). Isso porque o acesso a informações sobre práticas de PI em empresas é difícil, pois tais informações são tratadas como segredo (Candelin-Palmqvist et al., 2012). Este estudo abraça o objeto menos pesquisado: a gestão de PI em empresa de uma perspectiva estratégica.

A busca bibliográfica, em 12 de novembro de 2011, no The Journal of World Intellectual Property (Recuperado 12 novembro, $2011 \mathrm{de} \mathrm{http://www.wiley.com/bw/journal.asp?ref=1422-2213),}$ com base na expressão Intellectual Property Management, levou a 257 artigos. Considerando-se o período de 2007-2011, no corpo do texto, abstracts, títulos e key words, o número anterior caiu a 60 e a zero, respectivamente. A análise dos abstracts dos 60 artigos do journal antes referido indicou foco em: sistemas de propriedade intelectual de países ou regiões (Bernieri, 2006; Sterckx \& Cockbain, 2010); em pirataria (e.g., El-Bialy \& Gouda, 2011); em patentes (e.g., Sterckx \& Cockbain, 2010); em denominações de origem (e.g., Yeung \& Ker, 2011); em efeitos sobre investimento estrangeiro (e.g., Bernieri, 2006), desenvolvimento de países (e.g., Blakeney \& Mengistie, 2011) e inovação (e.g., Gervais, 2009), dentre outros. Artigos com foco em sistemas empresariais de gestão da propriedade intelectual não foram localizados.

A visita ao site Science Direct, em 24 de setembro de 2012, permitiu constatar que, dos 25 artigos mais relevantes, apenas 1 - Business Models, Business Strategy and Innovation (Teece, 2010) - trata de modelo de negócio (gestão) e suas interfaces com estratégias empresariais e de inovação em indústrias. Embora não identificados nas buscas antes citadas, mas integrando a base Science Direct, Pitkethly (2001) faz escrutínio das estratégias de PI em empresas japonesas e do Reino Unido, enquanto Hanel (2006) revisa bibliografia sobre práticas de gestão de direitos de propriedade intelectual. Já Candelin-Palmqvist, Sandberg e Mylly (2012) apresentam revisão de bibliografia em gestão da inovação e de direitos de PI, apontando as seguintes tendências: adoção de método longitudinal; foco em nível empresarial; busca de identificação de nexos entre direitos de PI, desempenho das empresas e de suas áreas funcionais; e maior diversificação do grupo de pesquisadores, com a crescente inclusão daqueles oriundos de outras regiões, especialmente, da Ásia.

A produção acadêmica brasileira sobre PI é recente, embora incorpore, tendencialmente, a perspectiva multidisciplinar (Amorim-Borher, Avila, Castro, \& Paulino, 2007). Levantamento 
bibliográfico na base Scielo (http://scielo.org), em 20 de julho de 2011, utilizando-se o termo Propriedade Intelectual, indicou a existência de 17 artigos, enquanto apenas 4 artigos foram encontrados com uso da expressão Gestão de Propriedade Intelectual. Também levantamento bibliográfico realizado em revista específica corroborou a percepção de que o tema gestão de propriedade intelectual ainda é pouco estudado no Brasil. Na Revista Brasileira de Inovação (RBI) (http://www.finep.gov.br/revista_brasileira_inovacao/revista_ini.asp), a busca com base no termo Gestão de Propriedade Intelectual, em 20 de julho de 2011, levou a 10 artigos.

A análise dos artigos da Scielo e da RBI mostrou foco setorial, regional, nacional ou em instituições públicas ligadas à pesquisa e ao ensino no Brasil (e.g., Andrade et al., 2007; Carvalho, Salles, \& Paulino, 2002; Chaves, Oliveira, Hasenclaver, \& Melo, 2007; Tigre \& Marques, 2009; Vieira, Buainain, Dal Poz, \& Vieira, 2010), constituindo-se exceção a essa regra Costa, Porto e Feldhaus (2010), que escreveram sobre gestão da cooperação universidade-empresa por uma multinacional com atuação no Brasil. Observou-se também concentração de estudos atinentes a patentes, permanecendo o foco em setores ou em instituições públicas, notadamente, universidades da região Sudeste do país (e.g., Vieira et al., 2010). Novos estudos (e.g., Araújo, Barbosa, Queiroga \& Alves, 2010; Lima \& Santini, 2008) tratam, ainda que muito genericamente, de novas formas de proteção na sociedade da informação ou outros institutos de PI (e.g., Kretzer \& Toyama, 2008), conquanto outros focam a relação entre PI e crescimento econômico (e.g., Herscovici, 2007; Mello, 2009), experiências internacionais e lições a serem aprendidas pelos agentes brasileiros (e.g, Andrade et al., 2007; Chaves et al., 2007).

Algumas das lacunas identificadas com base nessas buscas bibliográficas foram: ausência de estudos sobre sistemas de gestão de PI de empresas; foco concentrado em regiões e países (União Europeia, América Latina, França, Austrália, Índia, Uganda, Portugal, Estados Unidos, Reino Unido, Brasil e sudeste do Brasil); barreiras ao acesso de dados empresariais; utilização de dados secundários ou de survey cross section, em nível nacional, regional ou setorial; e tratamento preponderante a partir de abordagens econômicas, negligenciando-se as do campo da administração e da gestão. Em paralelo, notou-se que o tema PI é vasto, multidisciplinar e transversal; vem crescendo em importância; e seu debate tem se intensificado, com correntes favoráveis ao pleno uso dos sistemas que operacionalizam a proteção e a apropriação das criações, configurados nacional e internacionalmente, e outras de questionamento quanto a seus benefícios.

A evolução do campo de estudos sobre PI, assim como as lacunas encontradas na literatura, o imperativo de maior difusão do assunto e a necessidade de aprofundar o conhecimento sobre PI para além dos indicadores cartoriais motivaram a realização deste estudo de caso, cujo objetivo geral é identificar o alinhamento entre práticas de gestão de PI da Braskem S.A. e o postulado pela literatura em termos de orientação estratégica. A Braskem foi escolhida como caso exemplar por ter uma unidade no Polo Petroquímico de Camaçari (BA) e se destacar no conjunto de empresas que operam no estado em termos de obtenção de patentes de invenção.

$\mathrm{Na}$ próxima seção, são apresentados e discutidos os principais conceitos envolvidos na elaboração do estudo de caso, seguindo-se o registro do método utilizado. Na seção de resultados, os dados da Braskem S.A. são descritos e confrontados com a literatura revisada. Nas conclusões, os objetivos são retomados, sintetizando-se resultados encontrados e são indicados limites e contribuições do trabalho realizado.

\section{Marco Conceitual}

Esta seção registra o marco conceitual que norteou a elaboração do trabalho. Inicia-se com a delimitação dos conceitos e tipos de PI, assim como de gestão em geral e de gestão e estratégia de PI em particular. Essas discussões conceituais, assim como a revisão do estado do campo, ampararam a definição do problema de pesquisa e do modelo de análise. 


\section{Conceitos e tipos de PI}

Propriedade intelectual refere-se aos direitos inerentes à atividade intelectual, outorgados pelo Estado ao detentor da obra por prazo determinado. Alcança as obras literárias, artísticas e científicas, expressando-se na forma de PI e de Direito Autoral e Conexos (Andrade et al., 2007; Hanel, 2006). Os principais institutos de PI e suas definições encontram-se na Tabela 1.

Tabela 1

Principais Instrumentos de Direito de Propriedade Intelectual (DPI)

\begin{tabular}{ll}
\hline Denominação & Definição/aplicação \\
\hline Marca & $\begin{array}{l}\text { Conjunto de um ou mais sinais indicativos que individualiza determinado produto ou } \\
\text { serviço, ou um grupo deles, necessariamente associado a um empreendimento de } \\
\text { qualquer natureza. }\end{array}$ \\
\hline Patente & $\begin{array}{l}\text { Título de propriedade temporária, concedido pelo Estado à pessoa(s) física(s) ou } \\
\text { jurídica(s), tendo em vista a criação de algo novo para o estado da técnica e passível } \\
\text { de ser realizado industrialmente. Podem ser privilégios de invenção ou modelos de } \\
\text { utilidade. }\end{array}$ \\
\hline Nome de domínio & $\begin{array}{l}\text { Designação que serve para localizar e identificar conjuntos de computadores na } \\
\text { internet, tendo sido concebido para facilitar o uso dos endereços eletrônicos. }\end{array}$ \\
\hline Desenho industrial (DI) & $\begin{array}{l}\text { Forma plástica ornamental de um objeto ou o conjunto ornamental de linhas e cores } \\
\text { que possa ser aplicado a um produto, proporcionando resultado visual novo e original } \\
\text { na sua configuração externa e que possa servir de tipo de fabricação industrial. }\end{array}$ \\
\hline Direito do autor & $\begin{array}{l}\text { Direito voltado ao reconhecimento da autoria sobre uma determinada obra intelectual, } \\
\text { expressa em qualquer meio ou fixada em qualquer suporte, tangível ou intangível. }\end{array}$ \\
\hline Segredo industrial & $\begin{array}{l}\text { Meio de proteção do bem intelectual assegurado por cláusulas específicas, inseridas } \\
\text { em contratos de know-how, acordos de confidencialidade e similares. }\end{array}$ \\
\hline
\end{tabular}

Nota. Fonte: Lei $n^{\circ}$ 9.279, de 14 de maio de 1996. Regula os direitos e as obrigações relativas à propriedade industrial. Diário Oficial. Brasília, DF: República Federativa do Brasil. Recuperado de http://www.planalto.gov.br/ccivil_03/Leis/L9279.htm

Os institutos de PI focados neste trabalho são: marca, patente, nome de domínio, desenho e segredo industrial.

\section{Modelo de gestão e estratégias}

Toda empresa possui um modelo de negócio, explícito ou implícito, que orienta as atividades de criação e de entrega de valor, de geração de lucro e evidencia mecanismos empregados para tanto. Em qualquer setor, modelos de negócio de sucesso viabilizam respostas tempestivas a essas questões, são difíceis de imitar e afetam a longevidade dos empreendimentos. Se a empresa não possui modelo de negócio consistente com seu ambiente competitivo tende a ser superada por seus competidores ainda que possua tecnologia e produtos avançados, e mão de obra e liderança bem-formadas (Teece, 2010).

Nos campos da administração e da economia, não se pode dizer que o conceito de modelo de gestão de negócios encontre-se consolidado. Seja devido à centralidade e à ubiquidade do construto mercado, em função do que o papel das organizações empresariais é minimizado. Seja ainda porque, em estudos organizacionais, de estratégia e de marketing, há tendência a igualarem-se novas formas de organização a modelos de gestão de negócios, negligenciando-se o fato de que essas novas formas de organização são componentes de modelos de gestão de negócio, mas não são o próprio modelo (Teece, 2010).

Nova fonte de dificuldade deriva do fato de que o conceito de gestão é difícil de precisar (Santos, Guimarães, Melo, \& Sanchez, 2006). Também, o estudo de modelos de gestão exige enfoques 
interdisciplinares, condição essa não atendida pela literatura de organização e de estratégia, muito frequentemente. Em consequência, essa literatura menciona muito o construto modelo de gestão de negócios, mas raramente o analisa, tendendo também a confundir modelo de negócio com estratégia (Teece, 2010).

Estreitando mais ainda o foco ao campo da administração, observa-se que o conceito de gestão apresenta um caráter mais operacional e instrumental de função voltada para a coordenação e controle (Santos et al., 2006). Embora dimensões operacionais e instrumentais sejam vitais, a gestão transcende essas dimensões, abarcando também a capacidade de pensar o negócio, de formular seu modelo e de definir suas estratégias (Teece, 2010). A capacidade de gestão pode ser aferida pelas seguintes capacidades e condições: capacidade de formular políticas, estratégias, projetos e normas procedimentais; capacidade de articular e de mobilizar alianças e parcerias, assim como recursos políticos e estratégicos, visando a assegurar condições para a efetivação dos objetivos perseguidos por meio das políticas, planos, programas e projetos; e condições técnicas e administrativas (recursos humanos, materiais e financeiros) (Santos et al., 2006). As estratégias, em especial, atravessam transversalmente todas essas capacidades no sentido de que demandam competências e recursos variados tanto para sua formulação quanto para seu monitoramento e avaliação.

Modelos de gestão são mais genéricos que as estratégias empresariais. Se seus vários componentes forem complementares e formarem conjuntamente um sistema, constituem pilares das capacitações dinâmicas das empresas. Em combinação com os modelos de gestão, estratégias empresariais envolvem segmentação de mercado, definição da importância, de objetivos e metas para cada segmento, assim como a indicação de caminhos para atingi-los, e a instituição de mecanismos que protejam o modelo de negócio de perda de clientes e de imitação por competidores (Teece, 2010).

\section{Gestão e estratégia de PI}

A aplicação de direitos de PI torna os conhecimentos mais explícitos e protegidos, o que, por sua vez, aumenta a importância da gestão de PI. A gestão de PI se ramifica em interna, externa, tática e estratégica, compreendendo formas de funcionamento dos órgãos de PI, gestão de suas interações com outros departamentos e interações com outras empresas e instituição. Objetiva assegurar a proteção dos ativos de PI, abarcando o planejamento, a organização e a execução de atividades ligadas à PI aplicáveis a produtos e processos inovadores. Inclui atividades ligadas à apropriação da inovação propriamente dita, por meio de patentes, direitos de autor, DI, marcas e segredo industrial e ao estabelecimento de políticas e diretrizes. Encontram-se ainda, no escopo da gestão de PI, atividades de aquisição, licenciamento e transferência de tecnologia, bem como de celebração de acordos de cooperação (open innovation) (Candelin-Palmqvist et al., 2012; Hanel, 2006; Pitkethly, 2001).

Já a estratégia de PI corresponde à utilização, de modo isolado ou em combinação com outros recursos, de PI com vistas a alcançar os objetivos estratégicos das empresas. Estratégias dinâmicas de PI envolvem desenvolvimento contínuo de direitos de PI com vistas a manter sob controle o fluxo de tecnologia e posições na corrida tecnológica mais do que erigir barreiras para preservar posições competitivas (Pitkethly, 2001).

A existência de escritórios de PI e de transferência de tecnologia (EPITT), ou seja, de estruturas que se responsabilizam pela PI e pela Transferência de Tecnologia (TT) nas organizações, mostra-se associada ao sucesso da gestão dos ativos de PI e TT. Tais estruturas são centralizadas e internalizadas ou não, existindo situações em que há mais de um escritório por organização, uma estrutura para várias organizações, ou, ainda, organismos com atuação geográfica específica (Chamas, 2003).

Os EPITT são geralmente responsáveis pela implantação e monitoramento de políticas e práticas institucionais sobre PI e TT, cujas eficácias são funções da coerência com as missões e objetivos das organizações e com suas estruturas e escopos de pesquisas. Além disso, se de estrutura flexível, mostram-se mais responsivos à evolução das legislações nacionais e internacionais, bem como a situações imprevistas (Chamas, 2003). 
O escopo de atuação dos EPITT compõe-se de ações de proteção dos ativos, de marketing, de negociação e exploração econômica, de salvaguarda dos direitos protegidos contra terceiros e de disseminação do uso e exploração do sistema de PI como fonte de informação tecnológica. Além disso, geralmente, também, são os organismos mais apropriados para facilitar a aproximação e a cooperação entre universidades e empresas (Chamas, 2003).

Tabela 2

\section{Perfis Profissionais dos EPITT}

\begin{tabular}{|c|c|}
\hline Cargos & Perfis profissionais e funções \\
\hline \multirow[t]{7}{*}{ Agentes de propriedade industrial } & $\begin{array}{l}\text { Empregados ou terceirizados, com formação técnica em engenharias, } \\
\text { ciências naturais e conhecimentos sobre legislação que regula o tema. }\end{array}$ \\
\hline & Redação dos pedidos de patente e de desenho industrial (DI). \\
\hline & Definição de estratégias de proteção. \\
\hline & Realização de levantamentos do estado da técnica. \\
\hline & Depósito e acompanhamento de pedidos. \\
\hline & Respostas às exigências de órgãos competentes. \\
\hline & Atuação na manutenção das concessões, incluindo combate à contrafação. \\
\hline
\end{tabular}

Especialistas em marketing e exploração econômica da PI e TT
Possuem habilidades de comunicação e conciliação de distintos interesses em tecnologias e ciências, e de prospecção de mercados.

Atuam próximos aos agentes no acompanhamento do portfólio de ativos. Monitoram tendências de mercado das tecnologias que mantêm relação com o portfólio ou área de atuação da organização; identificam e contatam potenciais parceiros.

Realizam negociações e redação de instrumentos aplicáveis e acompanhamento das parcerias firmadas.

Preferencialmente, atuam em conjunto com o agente nas decisões de patenteabilidade e outros tipos de proteção, e nas revisões das políticas de PI e TT.

Especialistas em suporte administrativo, correspondência e outros
Atividades de apoio na manutenção e controle do portfólio de ativos.

Acordos de negócios.

Cálculos e monitoramento da distribuição dos royalties

Nota. Fonte: Adaptado de Chamas, C. I. (2003). Gerenciamento da proteção e exploração econômica da propriedade intelectual. Revista de Administração Pública, 37(5), 1055-1081.

Para realizar suas funções, os EPITT contam, em regra, com pessoal capacitado e treinado nas especificidades da PI e TT e no tratamento gerencial de seus ativos correlatos (Tabela 2), verificandose associação positiva entre o pessoal envolvido no suporte às atividades de inovação e a obtenção da proteção aos ativos (Chamas, 2003).

\section{Revisão do estado do campo}

Carvalho, Salles e Ferreira (2005) mostram que o sistema de proteção à PI é regressivo em relação ao porte das empresas, além de ser muito baixa a utilização de sistemas de proteção pelas empresas brasileiras. Salles, Ferreira e Carvalho (2006) apontam que a proteção intelectual é considerada central na estratégia de empresas que destacam a tecnologia e a inovação como vantagens competitivas relevantes.

Empresas japonesas e dos Estados Unidos destacam-se comparativamente às empresas europeias por incorporar questões relativas a patentes em suas estratégias competitivas. Especialmente no caso das empresas japonesas, observa-se progressiva incorporação dos Direito de Propriedade 
Intelectual (DPI) a suas estratégias de inovação, maior canalização de recursos à proteção de PI e, simultaneamente, o fortalecimento (mais status e poder) de seus departamentos de PI. A utilização de patentes varia de indústria a indústria, dependendo não apenas do fato de a tecnologia ser discreta ou complexa, mas também da estrutura competitiva da indústria. Em indústrias de tecnologia discreta, como a química e a farmacêutica, os direitos de PI relativos a produtos específicos ou a categorias de processo protege-os de imitações de forma mais efetiva que em outros campos. A estratégia de PI procura erigir um muro protetor em torno da inovação. Ainda nessas indústrias, patentes de invenção são facilmente licenciadas, mas raramente observa-se licenciamento cruzado, verificando-se o contrário em indústrias de tecnologias complexas (e.g., semicondutores e TICs). O uso efetivo de direitos de PI e sua incorporação às estratégias competitivas das empresas são mais frequentes no caso de grandes empresas e multinacionais do que de pequenas. Nas pequenas empresas, verificam-se lacunas de competência e reduzida capacidade financeira para registar e defender-se da infração a seus direitos. A valoração de PI, cujas métricas estão em evolução, é etapa importante de sua gestão, mostrando-se crucial para decisões de comercialização de tecnologias, licenciamento, fusões e aquisições (Hanel, 2006).

Herscovici (2007) assevera que os institutos de PI viabilizam mais a apropriação de rendas indiretas, constituídas pela formação e ampliação de barreiras à entrada e de vantagens concorrenciais que derivam das inovações, do que de rendas diretas. Sinaliza ainda a maior complexidade para a definição da titularidade dos direitos de propriedade, requerendo a negociação de patentes cruzadas, nos casos de open innovation.

Rosas, Froehner e Sbragia (2007) postulam que decisões de investimento em PI podem variar de acordo com o ciclo de vida da empresa, a estratégia de entrada no mercado, o tipo de inovação, o foco do modelo de inovação, as fontes de recursos, a fonte da inovação, o tamanho dos concorrentes, a área geográfica de atuação e o volume de capital investido.

Amorim-Borher, Avila, Castro e Paulino (2007) consideram ainda pouco difundida a prática de utilização de informações tecnológicas de patentes por empresas brasileiras, o que leva a óbices nas orientações das atividades de P\&D. Luna e Baessa (2008) evidenciam que firmas depositantes de marcas e patentes singularizam-se por maior tempo de estudo de seus empregados. Observam a expansão das atividades de ensino e pesquisa em PI. Bessen e Meurer (2008) demonstram a ocorrência de importantes efeitos diretos sobre o crescimento econômico, associada à qualidade das instituições de direitos de propriedade em geral, enquanto os direitos de propriedade intelectual apresentam efeitos fracos e indiretos. Outra evidência coletada foi a de que efeitos positivos de sistemas de patentes parecem sofrer contingências das tecnologias adotadas e do tipo de indústria. Mello (2009) defende que os impactos da utilização de patentes não são diretos nem absolutos, sendo fortemente condicionados pelos padrões de concorrência setorial. Conclui que os efeitos da proteção jurídica à PI são ambíguos - tanto incentivadores da inovação quanto restritivos da concorrência.

Candelin-Palmqvist et al. (2012) relatam que há poucos estudos sobre DPI entre os anos de 1970 e 1990, quando, então, o número de publicações começa a crescer. Pesquisas nessa área tendem a privilegiar o recorte geográfico, seus autores, em geral, são filiados a universidades europeias e, consequentemente, o contexto de análise da Europa é dominante. Ainda assim, questões geograficamente localizadas nos EUA e na Ásia aparecem mais do que poderia se inferir a partir da afiliação dos pesquisadores. Verificam ainda a progressiva internacionalização das pesquisas publicadas, com a participação em especial de pesquisadores da Ásia. Registram também que: em termos de nível de análise raramente encontram-se estudos em nível das firmas, com $90 \%$ dos artigos analisando o nível macro (e.g., indústria ou país); e predominam dados secundários, seja em função da perspectiva macro, seja ainda porque é muito difícil coletar dados em nível das firmas, os quais são, em regra, considerados confidenciais.

Infere-se de parte da bibliografia revisada (Hanel, 2006; Luna \& Baessa, 2008; Rosas, Froehner, Sbragia, 2007; Salles et al., 2006) que a propriedade e a gestão dos ativos de PI estão diretamente ligadas ao sucesso organizacional, embora seus impactos, especialmente das patentes, não sejam diretos, nem universais, variando por tipo de tecnologia, estrutura competitiva da indústria, porte 
(grande ou pequena) e tipo da empresa (nacional ou multinacional) (Bessen \& Meurer, 2008; Herscovici, 2007; Mello, 2009). Apesar dessa importância, estudos sobre gestão de PI em empresas e com dados primários são escassos (Candelin-Palmqvist et al., 2012), a utilização de sistemas de proteção de PI ainda é muito baixa no Brasil (Carvalho, Salles, \& Ferreira, 2005), assim como a difusão da utilização de informações patentárias e de estratégias empresariais em relação à PI (Amorim-Borher et al., 2007).

As práticas organizacionais relativas aos ativos de PI, por sua vez, parecem variar com ciclo de vida, estratégias competitivas, intensidade tecnológica de produtos e processos, tipos de tecnologias, origem do capital, porte, existência de estruturas dedicadas a pesquisa, estruturas de mercado e dinamismo dos setores produtivos em cada país (Bessen \& Meurer, 2008; Carvalho, Salles, \& Ferreira, 2005; Mello, 2009; Rosas et al., 2007). Práticas de valoração de ativos de PI podem ser adotadas tanto para viabilizar transações quanto para integração do valor desses ativos ao patrimônio das empresas que os detêm.

A revisão de bibliografia evidencia resultados inconclusivos, às vezes, contraditórios, sinalizando a existência de lacunas de conhecimentos, sobretudo em relação às práticas empresariais de gestão de ativos de PI, assim como sobre o alinhamento entre tais práticas e as estratégias competitivas das empresas. Em função disso, os problemas de pesquisa deste trabalho são: Que práticas de gestão de ativos de PI - marcas, patentes de invenção, desenhos e segredos industriais, modelos de utilidade e domínios de internet - foram adotadas pela Braskem S.A., entre 1998 e 2008 ? Essas práticas mostram-se alinhadas à literatura revisada?

\section{Modelo de análise}

O crescimento da importância da PI requer mudanças na forma como as empresas e, por extensão, os gestores visualizam e utilizam os ativos de PI. A PI pode ser fonte de inovação, criatividade e crescimento, requerendo, para tanto, tratamento estratégico.

O modelo de gestão de PI adotado compreende duas dimensões: a operacional (capacidade de executar), que indica iniciativas de gestão no sentido de manter e ampliar as condições logísticas e de mobilização de recursos organizacionais; e a estratégica, que se traduz em capacidade de formular e implementar estratégias e políticas que viabilizem a expansão de forma sustentável (Chamas, 2003; Santos et al., 2006; Teece, 2010). O detalhamento desse modelo encontra-se na Tabela 3.

Tabela 3

\section{Modelo de Análise}

\begin{tabular}{|c|c|c|c|}
\hline Conceito & Dimensões & Componentes & Indicadores \\
\hline \multirow[t]{3}{*}{$\begin{array}{l}\text { Gestão de } \\
\text { Propriedade } \\
\text { Intelectual (PI) } \\
\text { em empresas }\end{array}$} & \multirow[t]{3}{*}{ Estratégica } & $\begin{array}{l}\text { Estrutura } \\
\text { organizacional }\end{array}$ & $\begin{array}{l}\text { Setores envolvidos; articulações entre os setores; posição } \\
\text { hierárquica dos setores envolvidos; envolvimento no processo } \\
\text { decisório de PI; tipologia da estrutura destinada à PI; formas } \\
\text { de organização do trabalho e processos de trabalho de PI; } \\
\text { fluxos de comunicação sobre PI. }\end{array}$ \\
\hline & & $\begin{array}{l}\text { Políticas e } \\
\text { objetivos }\end{array}$ & $\begin{array}{l}\text { Existência de política de inovação ou política de PI: } \\
\text { autoridade e monitoramento; alinhamento entre estratégia, } \\
\text { objetivos empresariais e política de PI; escopo da política de } \\
\text { PI. }\end{array}$ \\
\hline & & $\begin{array}{l}\text { Exploração } \\
\text { econômica }\end{array}$ & $\begin{array}{l}\text { Modalidades adotadas; benefícios obtidos (diretos ou } \\
\text { indiretos); formas de pagamento ou recebimento; valoração } \\
\text { dos ativos de PI. }\end{array}$ \\
\hline
\end{tabular}


Tabela 3 (continuação)

\begin{tabular}{|c|c|c|c|}
\hline Conceito & Dimensões & Componentes & Indicadores \\
\hline \multirow{3}{*}{$\begin{array}{l}\text { Gestão de } \\
\text { Propriedade } \\
\text { Intelectual (PI) } \\
\text { em empresas }\end{array}$} & \multirow[t]{3}{*}{ Operacional } & $\begin{array}{l}\text { Organização do } \\
\text { trabalho }\end{array}$ & $\begin{array}{l}\text { Tamanho da equipe, divisão do trabalho, vínculo e dedicação } \\
\text { da equipe; perfil dos profissionais; funções desempenhadas. }\end{array}$ \\
\hline & & $\begin{array}{l}\text { Portfólio de } \\
\text { Ativos }\end{array}$ & $\begin{array}{l}\text { Tipologia e descrição de ativos; territorialidade dos ativos; } \\
\text { avaliação dos ativos. }\end{array}$ \\
\hline & & Procedimentos & $\begin{array}{l}\text { Fluxo e descrição de atividades; instrumentos ou modelos } \\
\text { utilizados; controle de serviços de terceiros especializados. }\end{array}$ \\
\hline
\end{tabular}

Nota. Fonte: Elaboração própria

Na primeira dimensão, a estratégica, englobam-se componentes e respectivos indicadores que permitem evidenciar suas estratégias competitivas e de que modo a empresa se organiza para gerir a PI, abarcando o processo decisório, a divisão do trabalho e processos de comunicação; as políticas que orientem as práticas da empresa e seu alinhamento às estratégias empresariais; as diretrizes quanto à exploração econômica dos ativos intangíveis. A dimensão operacional, por sua vez, complementa a definição do conceito de gestão de PI, ao provocar e viabilizar a investigação sobre procedimentos adotados, equipe envolvida e portfólio de ativos.

\section{Método}

Reúnem-se, nesta seção, a definição do tipo de pesquisa, das fontes, dos entrevistados, dos instrumentos de pesquisa, assim como a explicitação dos procedimentos de coleta e de tratamento dos dados coletados.

\section{Objetivos geral e específicos}

O objetivo geral é identificar o alinhamento entre práticas de gestão de ativos de PI da Braskem S.A. e o que é postulado pela literatura em termos de orientação estratégica. Já os específicos são: contextualizar e caracterizar a empresa pesquisada, suas inovações e sua estrutura de mercado; descrever seu modelo de gestão de PI; verificar a relação entre suas práticas de gestão dos ativos de PI e suas estratégias.

\section{Tipo de pesquisa e procedimentos de coleta e de tratamento dos dados}

O levantamento de processos de concessão de ativos a empresas sediadas na Bahia, nas modalidades da Propriedade Industrial - Patente de Invenção, Modelo de Utilidade e Desenho Industrial - com o corte temporal de 1990 a 2006, indicou que 36 patentes de invenção foram concedidas a 22 empresas em operação na Bahia, no período. Dessas 22 empresas, seis (Copene, CQR Polialden, Politeno, Pronor e Trikem) foram incorporadas pela Braskem S.A. A Estireno do Nordeste (EDN) foi comprada pela Dow Química, além de empresas que deixaram de ser sediadas no estado, como a Rhodia. A Braskem concentra $40 \%$ das patentes concedidas, tendo a segunda colocada (Dow Química), apenas $10 \%$. Cerca de $25 \%$ do total de 358 solicitações de depósitos de DI estão em nome de 43 empresas domiciliadas, à época, no estado, e a Braskem S.A. detém 9\% das solicitações de depósitos de DI da Bahia.

Como o universo a ser pesquisado é relativamente pequeno e o fenômeno em foco é ainda pouco estudado, a estratégia metodológica adotada foi a de estudo de caso. A Braskem S.A. foi escolhida como caso exemplar. O estudo de caso envolveu o levantamento de dados e informações em várias fontes: documentos, bibliografia, base de dados sobre PI e entrevistas com os principais interlocutores da empresa em PI. Em 10/10/2008, foi entrevistada a responsável pela área de PI, lotada 
na unidade de Triunfo, no Rio Grande do Sul. Em 24/10/2008, foi entrevistado o responsável pela área de Vinílicos, em São Paulo, Camaçari e Alagoas, e, em 20/11/2008, a Gerente Jurídica. Todos os registros das entrevistas foram submetidos à validação dos entrevistados por e-mail. $\mathrm{O}$ roteiro de entrevistas constou de 10 questões abertas versando sobre os componentes do modelo de análise (estrutura organizacional, políticas e objetivos, exploração econômica, organização do trabalho e procedimentos).

O tratamento das informações foi realizado, predominantemente, por meio de análise de conteúdo, cujas categorias foram as mesmas do modelo de análise antes mencionadas. De modo complementar, para tratamento de dados quantitativos, foram utilizadas medidas de estatística descritiva.

\section{Estudo de caso}

Esta seção apresenta a empresa pesquisada e descreve suas práticas de gestão de PI, tendo como norte o modelo de análise antes comentado. Os dados e informações coletados nas entrevistas referemse ao horizonte temporal de 1998 a 2008. Já os dados de desempenho da organização alcançam até 2010.

\section{Braskem S.A.: histórico, estratégia competitiva, desempenho e portfólio de inovações}

Controlada pela Organização Odebrecht, a Braskem S.A. é uma empresa de capital aberto. Foi fundada em 16 de agosto de 2002, pela integração dos ativos petroquímicos dos grupos Odebrecht e Mariani à Copene Petroquímica do Nordeste S.A., antiga central de matérias-primas petroquímicas do Polo de Camaçari, na Bahia, cujo controle acionário já pertencia àqueles grupos desde julho de 2001. Em 2004, incorporou as empresas OPP Química S.A., Nitrocarbono S.A., Trikem S.A. e Proppet S.A. A incorporação da Polialden Petroquímica S.A. ocorreu em maio de 2006; e a da Politeno Indústria e Comércio S.A. em maio de 2007. Em setembro de 2008, ocorreu a incorporação da Ipiranga Petroquímica, incluindo a Copesul, da Petroquímica Paulínia e de parte da Ipiranga Química (Braskem, n.d.a).

A estratégia empresarial que dá origem à Braskem segue tendência mundial de verticalização e de diversificação da produção petroquímica. Efetiva-se por meio de fusão e incorporação, concentrando as operações em grupos de famílias de produtos escolhidos por critérios tecnológicos e mercadológicos. Busca liderança de mercado, tanto do ponto de vista comercial e de market share quanto tecnológico, autonomia tecnológica e excelência operacional (Guerra, 2007).

Segundo os entrevistados, a estratégia mercadológica objetiva manter o ritmo de crescimento e acelerar seu processo de internacionalização, prospectando novas fontes de matérias-primas competitivas. Ainda de acordo com as mesmas fontes, há forte imbricação entre estratégia mercadológica e estratégia tecnológica, o que viabiliza a geração e fabricação de produtos e aplicações inovadoras que, por sua vez, atendem a nichos de mercado, representam aplicações específicas ou aumentam o market share da empresa.

Novamente de acordo com os entrevistados, a proteção de produtos por marcas, apesar de relevante, não é o principal foco, pois, na área de atuação da empresa, produtos petroquímicos e resinas - as características técnicas e de desempenho são mais valorizadas do que a diferenciação por marca. A preocupação maior é com a marca Braskem e com sua associação à imagem de empresa inovadora do ponto de vista socioambiental, requisitos esses valorizados em seu ambiente competitivo, verificando-se coerência entre estratégias e ambiente competitivo (Teece, 2010).

Trata-se da primeira empresa petroquímica integrada do país, combinando operações da primeira e da segunda gerações, derivando daí vantagens competitivas, como escalas de produção e eficiência operacional. Apesar de atuar também na Ásia e na Europa, seu foco é o mercado das Américas, onde é líder na América Latina (AL) em resinas termoplásticas. É ainda líder mundial em 
biopolímeros e a terceira maior produtora de resinas termoplásticas. De 2002 a 2007, a Braskem S.A. registrou crescimento médio anual de $33 \%$ em receita líquida, faturamento médio anual de $\mathrm{R} \$ 24$ bilhões. Em 2008, o faturamento foi de R $\$ 23$ bilhões e foram produzidas 11 milhões de toneladas. Em 2010, faturou cerca de $\mathrm{R} \$ 35$ bilhões, enquanto sua receita de exportação alcançou $\mathrm{R} \$ 4,2$ bilhões. Suas 31 unidades industriais, 28 no Brasil (Alagoas, São Paulo, Rio de Janeiro, Rio Grande do Sul e Bahia) e 3 nos EUA, garantem-lhe uma capacidade instalada de 15 milhões de toneladas de resinas termoplásticas e outros produtos químicos, ainda em 2010 (Braskem, n.d.b).

Possui, em sua estrutura, o Centro de Tecnologia e Inovação Braskem (CTI), considerado o maior e o mais moderno centro de $\mathrm{P} \& \mathrm{D}$ na área petroquímica da $\mathrm{AL}$, no qual foram investidos US\$150 milhões. Até 2008, existiam três CTIs, localizados em Triunfo (SP) e Camaçari (BA). Atualmente, são dois CTIs, um no Brasil, em Triunfo (RS), e outro nos Estados Unidos, os quais contam com, aproximadamente, 240 profissionais (Braskem, n.d.b).

Por meio das unidades do CTI, a empresa busca agregar valor e competitividade empresarial. Para tanto, foram investidos, em 2010, cerca de $\mathrm{R} \$ 65$ milhões em $\mathrm{P} \& \mathrm{D}$, utilizados tanto internamente quanto em sua rede de $\mathrm{P} \& \mathrm{D}$, a qual é mantida por meio de acordos de cooperação com universidades e instituições de pesquisa do Brasil e do exterior (Braskem, n.d.b).

O número de patentes depositadas pela Braskem cresce a cada ano e atesta a efetividade de seus processos de inovação. Até 2008, eram 200 patentes. Hoje, já são mais de 420. Mensalmente, em média, 10 novos projetos são encaminhados para análise do potencial para transformarem-se em patentes. Nos últimos três anos, aproximadamente 12\% do faturamento da Braskem foram gerados por produtos desenvolvidos nos últimos três anos. Algumas inovações mais recentes empreendidas pela Braskem encontram-se na Tabela 4 (Braskem, n.d.b).

Tabela 4

\section{Principais Inovações da BRASKEM S.A.}

Inovações

Processo de produção de polipropileno aditivado com nanocompósitos (nanopartículas), configurando-se em primeira patente depositada de uma empresa petroquímica brasileira envolvendo nanotecnologia.

Produção de PVC com adição de nanopartículas diretamente no reator durante o processo de fabricação da resina.

Novas aplicações para polipropileno: copos descartáveis, potes para requeijão e telhas e caixas d'água.

Tecnologia Injection Stretch Blow Molding (ISBM) para produção de garrafas de polipropileno de bebidas não gasosas, permitindo o envase a quente.

Resinas Braskem Flexus para embalagens especiais que exigem maior brilho e resistência mecânica.

Braskem Symbios, selante em polipropileno biorientado, que garante melhor desempenho no fechamento de embalagens.

Resina UTEC, polietileno de ultra-alto-peso molecular, para revestimento de forte impacto.

Resina Idealis, polietileno de alto rendimento, destinado ao mercado externo, usada na fabricação de bases de corte para a indústria de alimentos e bases de montagem para indústria automotiva.

Resina Idealis, polietileno de alto rendimento, destinado ao mercado externo, usada na fabricação de bases de corte para a indústria de alimentos e bases de montagem para indústria automotiva.

Polietileno verde fabricado a partir do etanol da cana-de-açúcar.

Polipropileno produzido a partir de matéria-prima renovável

Nota. Fonte: Adaptado de Braskem. (n.b.b). Inovação. Recuperado de http://www.braskem.com.br/site.aspx/Inovacao. 
A Braskem corrobora o perfil da empresa brasileira que mais utiliza PI, traçado com base em Pitkethly (2001), Carvalho, Salles e Ferreira (2005) e Hanel (2006): é de grande porte, pertence ao setor industrial e possui estrutura interna de $\mathrm{P} \& \mathrm{D}$. Também suas estratégias empresariais mostram-se bem-sucedidas, assim, viabilizando o crescimento continuado da empresa e sua internacionalização (Teece, 2010).

\section{Gestão de PI: dimensão estratégica}

As subseções seguintes apresentam aspectos estratégicos da gestão de PI pela Braskem S.A., em conformidade com o modelo de análise.

\section{Estrutura organizacional voltada para PI}

À época da pesquisa, os setores de Inovação \& Tecnologia, Desenvolvimento de Mercado e de Engenharia de Processos envolviam-se com atividades de PI. Além desses, também participavam os setores Jurídico e de Marketing da área corporativa, que se articulavam com os demais setores ou áreas da empresa vinculados à PI em atividades mais operacionais e de suporte, mas que, por vezes, influenciavam decisões estratégicas.

Até 2008, as atividades de PI, conduzidas pela área de Inovação \& Tecnologia, em Triunfo, circunscreviam-se aos ativos ligados à estratégia tecnológica (patente de invenção, modelo de utilidade e DI), enquanto marcas e nomes de domínio eram acompanhados pelas áreas de Marketing e Jurídica, na esfera corporativa, em São Paulo.

Ainda no horizonte temporal da pesquisa, encontravam-se em funcionamento comitês de inovação, formados por representantes das áreas envolvidas no processo de inovação que articulavam os setores direta e indiretamente envolvidos com os ativos de PI. Havia ainda serviços terceirizados tanto em relação a patentes quanto a marcas.

Os fluxos de comunicação interna entre unidades e setores responsáveis pelas áreas de PI eram de natureza horizontal para as rotinas de trabalho, sendo usualmente utilizados como canal de comunicação o correio eletrônico, e de natureza vertical para informes mais estratégicos, veiculados em reuniões trimestrais dos comitês de inovação. Quanto à comunicação externa, as informações referentes aos ativos de PI (mais concentradas em patentes) eram selecionadas de acordo com seu caráter estratégico e não sigiloso, e repassadas à área de comunicação da empresa que as utilizava na elaboração de notícias e relatórios expostos no site da empresa, bem como de releases para a imprensa.

Em síntese, a organização das atividades de PI era descentralizada por natureza de ativos, assim como contava com equipes interna e externa. Os setores diretamente envolvidos eram Inovação \& Tecnologia e Jurídico. Tais setores operacionalizavam estratégias definidas pelas áreas de Negócio e Marketing. Não havia setor específico, na estrutura organizacional da empresa, para gestão de PI, a exemplo dos EPITT apresentados por Chamas (2003). A PI é considerada como ferramenta de gestão da inovação, embora não conte com estrutura específica de gestão.

Tomando-se como referência o conceito de gestão de Teece (2010) e de Santos, Guimarães, Melo e Sanchez (2006), a ausência de estrutura específica pode implicar falhas de coordenação, de capacidade de formular projetos, políticas e normas legais, além de escassez de condições técnicas e administrativas (recursos humanos, materiais e financeiros). Tudo isso pode refrear a capacidade da empresa de articulação e de mobilização de alianças e parcerias. Esses riscos são reforçados uma vez que o setor de Inovação \& Tecnologia, um dos principais articuladores das atividades relativas à PI, não se reporta diretamente ao Corporativo. 


\section{Políticas e objetivos}

Um dos objetivos do plano estratégico da Brasken S.A. é assegurar autonomia tecnológica por meio de processos de melhoria contínua e inovação, e de investimentos em P\&D, seja em seus CTIs, seja em parcerias com clientes, fornecedores e universidades nacionais e estrangeiras. Conquanto não exista qualquer documento com a denominação de política de inovação ou mesmo política de PI, a empresa explicita, em suas práticas, a existência de diretrizes e normas, algumas tácitas outras formais, para acompanhar o estado da arte das tecnologias empregadas no setor e para a proteção de suas inovações. O Programa Braskem de Inovação, que é um dos instrumentos da política de inovação e de PI, tem sua implementação acompanhada e ajustada pelos comitês de inovação.

Conforme os entrevistados, existem orientações para o patenteamento de inovações, que, após análise, sejam classificadas como inéditas e com valor comercial, elaboradas por um grupo de trabalho designado para esse fim e aprovadas pela diretoria da empresa. As orientações estabelecidas por tal grupo se destinam prioritariamente aos empregados que trabalham com criações técnicas. Os setores responsáveis pela gestão dos ativos de PI têm critérios definidos para a escolha das modalidades e dos países para proteção, os quais são confidenciais (Candelin-Palmqvist et al., 2012; Hanel, 2006).

Podem-se ressaltar, ainda, diretrizes da empresa com relação à titularidade de ativos que envolvem terceiros, estabelecidas no contrato de desenvolvimento conjunto. Quando envolvem clientes, os setores de Inovação \& Tecnologia ou de Desenvolvimento de Mercado trabalham alinhados com a área comercial; quando envolvem fornecedores ou Instituições Científicas e Tecnológicas (ICT), o contato, geralmente, fica centralizado no setor de Inovação \& Tecnologia, com o apoio do departamento Jurídico. A depender do grau de maturidade da tecnologia e das ações desenvolvidas pelas partes, a titularidade pode ser compartilhada ou não. Se a ideia for originária da Braskem, a titularidade é da empresa; caso contrário, há cotitularidade regulamentada em contrato.

Para o monitoramento das atividades de PI, o único indicador oficial acompanhado e divulgado é o número de depósitos da Braskem no Brasil e exterior. Os demais indicadores são utilizados em discussões e avaliações internas, a exemplo dos depósitos de ativos dos concorrentes. Servem mais como fonte de monitoramento tecnológico, sendo pouco utilizados para decisões; por isso, não há metas a eles relacionadas e não constam nos planos de ação das unidades.

Em suma, observou-se que não existe política formal de PI, embora haja diretrizes e normas tácitas ou formais que se mostram alinhadas à estratégia competitiva, tecnológica e mercadológica da empresa. Apesar da existência de diretrizes e normas, parece haver lacunas de orientações estratégicas, as quais podem ser supridas com a formulação de uma política de PI, conforme sugestão de Chamas (2003). A ausência de política formal de PI reflete uma lacuna em termos de sua gestão estratégica (Hanel, 2006; Santos et al. 2006; Teece, 2010). Novamente aqui, procedimentos em relação à open innovation fortalecem pesquisas revisadas, a exemplo de Herscovici (2007).

\section{Exploração econômica}

A Braskem S.A. não possui como estratégia atual a comercialização de seus ativos de PI. Os focos da empresa são: produzir com competitividade, apoiando-se em desenvolvimento tecnológico; adquirir portfólio por meio da incorporação de outras empresas ou joint-ventures no segmento em que atua; ou, ainda, realizar licenciamentos junto a terceiros. A decisão de aquisição ou desenvolvimento é baseada em estudos de viabilidade. Não foram identificadas práticas de valoração de ativos de PI, as quais compõem a gestão estratégica de PI (Hanel, 2006).

A empresa mantém acordos de sigilo com empregados, parceiros e fornecedores, elaborados pelo setor Jurídico, e os pesquisadores são nominados como inventores. No que se refere à repartição de benefícios originados pelo uso da tecnologia desenvolvida, os empregados envolvidos diretamente não têm direitos adicionais, pois tal atividade já está contemplada em seus contratos de trabalho. Eventualmente, pode haver remuneração indireta, por meio de participação de lucros, caso o 
desenvolvimento conste como meta no plano de ação da unidade e traga o retorno esperado e pactuado entre líder-liderado.

Em resumo, a Braskem S.A. obtém benefícios indiretos da exploração econômica de seus ativos, uma vez que privilegia ganhos associados ao lançamento de inovações no mercado (Hanel, 2006; Pitkethly, 2001). Considerando que as principais inovações da empresa são protegidas por patentes e marcas, seus benefícios podem ser verificados pelo comportamento do volume de vendas e de seu market share, já especificados em item anterior. Esses dados sugerem que a Braskem utiliza os ativos de PI para fortalecer suas posições competitivas e aumentar barreiras à entrada em seus segmentos de atuação. Isto é, com as vantagens concorrenciais usufruídas derivadas dos ativos de PI, a Braskem S.A. apropria-se de rendas indiretas a partir do fortalecimento de barreiras à entrada, conforme sinalizado por Herscovici (2007).

\section{Gestão de PI: dimensão operacional}

As subseções seguintes apresentam aspectos operacionais da gestão de PI pela Braskem S.A., em conformidade com o modelo de análise.

\section{Organização do trabalho}

A gestão de PI da Braskem S.A., do ponto de vista operacional e em linhas gerais, está centrada nas atividades de proteção, acompanhamento dos ativos próprios de PI e de terceiros, bem como sua salvaguarda. Essas atividades de gestão são realizadas por duas equipes, sendo que uma cuida de patentes e de DI; e outra, de marcas e de domínios de internet. As equipes internas contam com reforço de escritórios de advocacia especializados em propriedade industrial, que realizam algumas atividades específicas (Chamas, 2003).

A equipe de PI vinculada à Inovação \& Tecnologia atua na sensibilização e esclarecimento do público de pesquisadores (internos e externos) e demais colaboradores envolvidos com inovação de todas as unidades; na busca de anterioridade e acompanhamento da proteção legal de patentes e de DI, incluindo a gestão dos fornecedores contratados para tal; no monitoramento tecnológico para subsidiar novas pesquisas e tomadas de decisões; e no fornecimento de informações e indicadores relacionados à temática (Chamas, 2003; Pitkethly, 2001). Subordinava-se, até 2008, ao líder da área de Inovação \& Tecnologia de Poliolefinas (RS) e era formada por dois engenheiros químicos, sendo um sênior e outro júnior, e um estagiário da área de engenharia química, que se dedicavam integralmente às atividades de PI. O setor Jurídico, além de se responsabilizar pela proteção e acompanhamento das marcas, em conjunto com o Marketing, também atuava na salvaguarda dos direitos da empresa contra terceiros. O Marketing, por sua vez, cuidava de toda a estratégia para criação das marcas junto às unidades, envolvendo o comercial, sempre que necessário. Também se responsabilizava pelos domínios de internet em parceria com o setor de Informática.

A equipe externa era formada por escritórios de advocacia renomados na área de PI: Dannemann Siemsen, com sedes no Rio de Janeiro, São Paulo e Brasília, Momsen, Leonardos e Cia., com sede no Rio de Janeiro e filial em São Paulo e Guerra Advogados, sediados em Brasília. Os escritórios eram responsáveis pelas atividades de redação dos pedidos e pelo acompanhamento de todo o trâmite, incluindo a redação de petições, subsídios e demais documentos de natureza jurídica envolvidos no processo de proteção aqui e no exterior. Já os escritórios especializados, utilizados para os processos de marca, eram gerenciados pelo Jurídico, que não informou quais os utilizados, alegando confidencialidade. Aparentemente, os escritórios atuam tanto como procuradores dos pedidos junto aos escritórios oficiais de propriedade industrial no Brasil e no exterior quanto nas atividades de combate à contrafação (uso inapropriado dos ativos por terceiros).

Enfim, a empresa possui equipe dedicada e especializada, não sendo possível precisar seu exato tamanho (sabe-se que três pessoas trabalham diretamente com patentes e DI e, paralelamente, há utilização de escritórios especializados). As funções desempenhadas são, essencialmente, ligadas à 
proteção, acompanhamento e salvaguarda do ativo, além de monitoramento tecnológico e, em menor proporção, sensibilização dos colaboradores para uso da PI. Essas funções corroboram, em parte, especificações de Chamas (2003) .

\section{Portfólio de ativos}

Até 2008, a Braskem S.A. possuía como principal ativo as marcas (53\% do total), vindo a seguir patentes de invenção (45\% do total) e DI (2\%). Do total de pedidos de patentes, $91 \%$ dos processos ainda eram nacionais, $7 \%$ estavam na Argentina e 2\%, no Canadá. A concentração de processos no Brasil corrobora resultados de pesquisa de Hanel (2006) e Chamas (2003). Não foi possível identificar todos os países eleitos, mas ressalta-se que a Argentina era um dos mais importantes mercados consumidores dos produtos Braskem à época da pesquisa.

Também até 2008, a empresa detinha 200 patentes depositadas no Brasil, nos Estados Unidos e na Europa, além de oito registros de DI, e um conjunto de projetos, o que lhe permitia lançar constantemente novidades nos mercados, além de conquistar vários prêmios. Pesquisas na base de dados do INPI revelou que ainda havia processos de transferência pendentes.

A evolução dos pedidos da Braskem por tipo de ativo, no período de 1998 a 2008, evidencia constância no pedido de patentes, situação pontual dos DI depositados em 2004 e o resultado outlier de processos de marcas em 2001 e 2002. O período coincide com a incorporação das empresas que deram origem à Braskem e, com isso, infere-se que tenha ocorrido um movimento de transferência de titularidade de substancial portfólio de marcas daquelas firmas (Figura 1).

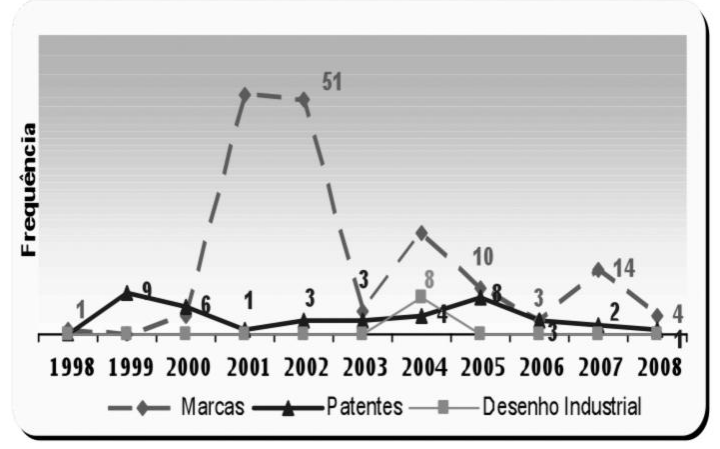

Figura 1. Evolução dos Pedidos de Ativos 1998-2008.

Fonte: Adaptado de Instituto Nacional da Propriedade Industrial. (n.d.a). Pesquisas. Bases de patentes, marcas. Portugal. Recuperado de http://www.inpi.pt/servicos/marcas_online.html; Instituto Nacional da Propriedade Industrial. (n.d.b). Pesquisas. Bases de patentes, marcas e desenhos industriais. Brasil, 2008. Recuperado de http://www.inpi.gov.br/menusuperior/pesquisas; United States Patent and Trademarks Office. (n.d.). Patents and trademarks databases. EUA. Recuperado de http://www.uspto.gov/index.html; Oficina de Armonización Del Mercado Interior. (n.d.). CTM Online - Servicio de consulta de marcas - Básico. Recuperado de http://oami.europa.eu/CTMOnline/RequestManager/es_Result_NoReg; Instituto Nacional de la Propiedad Industrial. (n.d.). Bases de datos. Argentina. Recuperado de http:// www.inpi.gov.ar

O portfólio de PI é analisado anualmente pelo representante da área de PI, pelo pesquisador ou inventor e pelo diretor da área envolvida. As decisões são encaminhadas para validação ao comitê de inovação, bem como à vice-presidência de todas as unidades e a especialistas. Os inventores e seus respectivos líderes são comunicados sobre a concessão ou a extinção dos documentos de suas autorias.

Com relação às classes de proteção dos pedidos de patentes (Figura 2), à exceção do resultado outlier NI (que significa classificação não identificada), verifica-se o predomínio das classes $\mathbf{C}$ (referente à química e à metalurgia), com $43 \%$ do total de pedidos classe B (operações de processamento e transporte), com $7 \%$, e classes $\mathbf{E}$ (construções fixas) e $\mathbf{G}$ (física), com $2 \%$ cada. 


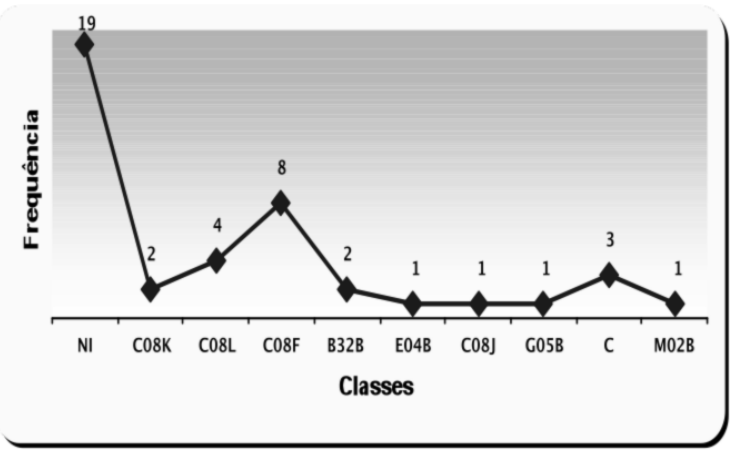

Figura 2. Pedidos de Patentes por Classe Solicitação.

Fonte: Adaptado de Instituto Nacional da Propriedade Industrial. (n.d.a). Pesquisas. Bases de patentes, marcas. Portugal. Recuperado de http://www.inpi.pt/servicos/marcas_online.html; Instituto Nacional da Propriedade Industrial. (n.d.b). Pesquisas. Bases de patentes, marcas e desenhos industriais. Brasil, 2008. Recuperado de http://www.inpi.gov.br/menusuperior/pesquisas; United States Patent and Trademarks Office. (n.d.). Patents and trademarks databases. EUA. Recuperado de http://www.uspto.gov/index.html; Oficina de Armonización Del Mercado Interior. (n.d.). CTM Online - Servicio de consulta de marcas - Básico. Recuperado de http://oami.europa.eu/CTMOnline/RequestManager/es_Result_NoReg; Instituto Nacional de la Propiedad Industrial. (n.d.). Bases de datos. Argentina. Recuperado de http:// www.inpi.gov.ar

Quanto às marcas, também não foi possível obter maiores detalhes sobre o portfólio, nem sobre critérios de gerenciamento, informações consideradas confidenciais pelos entrevistados. Contudo pesquisas exploratórias, realizadas em algumas bases de dados oficiais no Brasil e no exterior, que cobrem o período de 1998 a 2008, permitiram identificar que a maior frequência dos pedidos de proteção das marcas ocorre na classe 1, relacionada a substâncias químicas destinadas à indústria, seguida das classes 17 e 22, respectivamente, produtos em matérias plásticas semiprocessadas e serviços científicos e tecnológicos, pesquisa e desenho relacionado a estes; serviços de análise industrial e pesquisa (Figura 3).

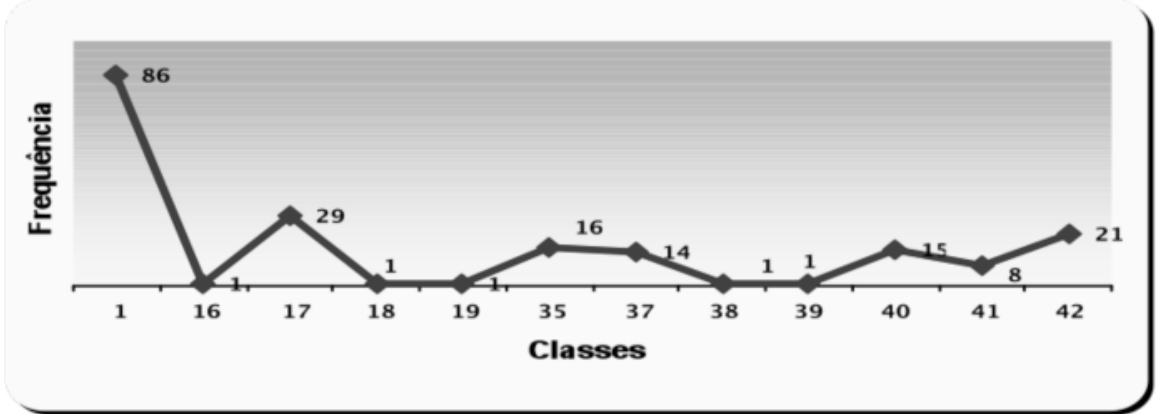

Figura 3. Pedidos de Marcas por Classes (Braskem).

Fonte: Adaptado de Instituto Nacional da Propriedade Industrial. (n.d.a). Pesquisas. Bases de patentes, marcas. Portugal. Recuperado de http://www.inpi.pt/servicos/marcas_online.html; Instituto Nacional da Propriedade Industrial. (n.d.b). Pesquisas. Bases de patentes, marcas e desenhos industriais. Brasil, 2008. Recuperado de http://www.inpi.gov.br/menusuperior/pesquisas; United States Patent and Trademarks Office. (n.d.). Patents and trademarks databases. EUA. Recuperado de http://www.uspto.gov/index.html; Oficina de Armonización Del Mercado Interior. (n.d.). CTM Online - Servicio de consulta de marcas - Básico. Recuperado de http://oami.europa.eu/CTMOnline/RequestManager/es_Result_NoReg; Instituto Nacional de la Propiedad Industrial. (n.d.). Bases de datos. Argentina. Recuperado de http:// www.inpi.gov.ar

Em busca na internet e tendo como referência o horizonte temporal da pesquisa, foram identificados os domínios braskem.com.br, braskem.com e braskem.com.ve, o que parece corroborar a estratégia de internacionalização da empresa (.com) e a importância dos acordos vigentes com o governo venezuelano (.ve) para as plantas do Polo Petroquímico de Jose. Contudo o domínio braskem.ind.br, voltado para a categoria indústrias, ainda está disponível para registro, assim como estão indisponíveis braskem.eu (comunidade europeia) e Braskem.us (Estados Unidos).

Em resumo, evidenciou-se que o portfólio de ativos de PI da Braskem S.A. compõe-se de marcas, domínios de internet, segredo industrial (declarado), patentes (de invenção, essencialmente) e DI, os quais estão geralmente protegidos no Brasil, fortalecendo pesquisas revisadas, mas há processos também na Argentina, Venezuela, Canadá, USA, UE. 


\section{Procedimentos}

Atividades relacionadas à PI, seus fluxos, responsáveis e prazos estão definidos, registrados e são divulgados para os envolvidos por meio de documentos específicos. Em linhas gerais, no caso de marcas, as unidades de negócio e/ou o setor comercial (marcas de produtos) ou outros setores (marcas de cunho mais institucional) procuram o Marketing, que passa a interagir com o Jurídico para a definição do tipo de proteção e dos mercados. Uma das primeiras etapas é a busca de anterioridade das marcas para identificação da disponibilidade do sinal. Com relação às patentes e ao DI, o pesquisador ou a área técnica envolvida procura a área de PI para comunicar o potencial de uma ideia ou o andamento de um projeto de inovação. A área de PI, então, realiza as seguintes macroatividades: pesquisa de anterioridade para patentes e DI; avaliação da opção pela proteção; apoio à redação e depósito dos pedidos; gestão do portfólio. Tais procedimentos estão em consonância com Chamas (2003).

O monitoramento tecnológico é também realizado pela área de PI. Suas macroetapas são: escolha e priorização das áreas de interesse; definição da estratégia de monitoramento (assuntos, players, ferramentas); divulgação das informações, análise e definição das ações. A concorrência é monitorada a partir de informações contidas em bases de patentes. Há modelos de relatório para disseminar as informações junto às áreas de interesse, que são emitidos trimestralmente para área de poliolefinas; e, semestralmente, para vinílicos, além da emissão de relatórios quinzenais com informações nacionais, a partir da Revista de Propriedade Industrial (INPI), e envio às áreas interessadas (Chamas, 2003; Hanel, 2006; Pitkethly, 2001).

A área de PI é responsável ainda pela contratação e acompanhamento dos serviços prestados por terceiros, mas não há instrumentos de controle, nem de verificação da eficácia da prestação desses serviços. Também, não foi possível apurar os gastos médios mensais. Os escritórios são responsáveis por monitorar os prazos dos processos e adotar as providências cabíveis.

\section{Conclusões}

Objetivou-se identificar, por meio de estudo de caso da Braskem S.A., selecionada pela sua representatividade no uso do sistema de PI, o nível de alinhamento entre suas práticas de gestão de PI e o postulado pela literatura em termos de orientação estratégica. Observou-se a vinculação entre práticas de PI e estratégia empresarial, especialmente, em suas vertentes tecnológica e mercadológica.

Apesar de terem sido evidenciadas muitas práticas em âmbito estratégico (aproximação entre as atividades relativas à PI e às estratégias tecnológicas e de marketing) e operacionais (existência de equipes especializadas e dedicadas, cujas atividades são complementadas por funcionários de outros setores da empresa e por escritórios especializados, e de práticas de prospecção tecnológica e de monitoramento de ativos de PI, próprios e de terceiros), considera-se que, em geral, a empresa ainda mostra algumas lacunas em termos de gestão estratégica de PI. A primeira delas é o fato de não existir um órgão específico para gestão de PI vinculado ao corporativo (localizado na unidade de São Paulo). Como abordado, as atividades de PI distribuem-se entre vários setores da empresa, embora haja uma relativa liderança do setor de inovação da unidade de Triunfo (RS), que é a maior responsável pela geração de inovações. Essa falta de ligação direta sugere que a gestão de PI ainda não é, de fato, considerada como fonte privilegiada de vantagem competitiva.

Não há também uma política formalmente definida em termos de gestão de ativos de PI, embora tenha sido identificada a existência de normas e procedimentos formais e tácitos em relação ao assunto. Sem a política, pode ocorrer ambiguidade na comunicação dos objetivos estratégicos, da missão, da visão e das estratégias relacionadas aos ativos de PI, assim como se torna difícil avaliar a contribuição da área de gestão estratégica de ativos de PI para o sucesso competitivo da empresa. Além disso, a Braskem S.A. não valora seus ativos de PI nem os gerencia como bens a serem 
comercializados. Para a empresa, as inovações e suas proteções são fontes de vantagens competitivas e não objetos de comercialização. Mesmo assim, a valoração é crucial porque impacta positivamente o valor de mercado da empresa, podendo ampliar suas vantagens competitivas. Como referido, estratégias dinâmicas de PI envolvem desenvolvimento contínuo de direitos de PI com vistas a manter sob controle o fluxo de tecnologia e posições na corrida tecnológica.

Com base nos resultados, pode-se concluir também que o alinhamento das práticas de PI da Braskem S.A. com o preconizado pela literatura revisada é parcial. Esse desalinhamento relativo parece refletir especificidades emanadas das estruturas de mercado da Braskem S.A., as quais são negligenciadas por parte da literatura corrente sobre PI, embora reflitam também lacunas em suas capacitações internas. É importante registrar, contudo, que a área de PI, na Braskem S.A., à época da pesquisa, estava em reestruturação com vistas a otimizar seu funcionamento, maximizar resultados e utilizar o potencial dos ativos de PI para maior suporte à estratégia empresarial.

Por último, registra-se que o estudo de caso permitiu focar em profundidade as práticas de PI da Braskem S.A., dessa maneira, contribuindo para ampliar conhecimentos sobre práticas de empresas inseridas em setores específicos e minimizar imprecisões conceituais. Não obstante seus resultados não possam ser generalizados empiricamente, considerando-se que a pesquisa realizada é um estudo de caso, a leitura de seus resultados com a aplicação de lentes teóricas contribui para ampliar o conhecimento sobre a realidade e as práticas empresariais no setor de atuação da Braskem S.A., sobretudo pelo fato de a empresa ser líder em muitos de seus mercados e áreas de atuação. Assim o conhecimento produzido é relevante tanto para o setor produtivo quanto para o desenvolvimento socioeconômico e tecnológico do país e do estado. Para as empresas, as informações geradas podem subsidiar aprimoramentos de suas práticas em área tão estratégica atualmente. Em termos do desenvolvimento, a ampliação do conhecimento gera insumos com vistas à proposição de políticas públicas voltadas para a intensificação da disseminação de conhecimentos sobre PI e para o balizamento e maior discricionariedade de políticas de incentivo à proteção de ativos de PI e seus instrumentos.

\section{Referências}

Amorim-Borher, B., Avila, J., Castro, A. C., \& Paulino, S. (2007). Ensino e pesquisa em propriedade intelectual no Brasil. Revista Brasileira de Inovação, 6(2), 281-310.

Andrade, E., Tigre, P. B., Silva, L. F., Silva, D. F., Moura, J. A. C. de, Oliveira, R. V. de, \& Souza, A. (2007). Propriedade intelectual em software: o que podemos apreender da experiência internacional? Revista Brasileira de Inovação, 6(1), 31-53.

Araújo, E. F., Barbosa, C. M., Queiroga, E. S. dos, \& Alves, F. F. (2010). Propriedade intelectual: proteção e gestão estratégica do conhecimento (Supl. Especial). Revista Brasileira de Zootecnia, 39, 1-10. doi: 10.1590/S1516-35982010001300001

Bernieri, R. C. (2006). Intellectual property rights in bilateral investment treaties and access to medicines: the case of Latin America. The Journal of World Intellectual Property, 9(5), 548572. doi: $10.1111 / \mathrm{j} .1422-2213.2006 .00302 . \mathrm{x}$

Bessen, J., \& Meurer, M. J. (2008, August). Do patents perform like property? Academy of Management Perspectives, pp. 8-20.

Blakeney, M., \& Mengistie, G. (2011). Intellectual property and economic development in subsaharan África. The Journal of World Intellectual Property, 14(3-4), 238-264. doi: 10.1111/j.1747-1796.2011.00417.x

Braskem. (n.d.a). Histórico - 2011. Recuperado de http://www.braskem.com.br/site.aspx/historico 
Braskem. (n.b.b). Inovação. Recuperado de http://www.braskem.com.br/site.aspx/Inovacao

Buainain, A. M., \& Carvalho, S. M. P. de (2000). Propriedade intelectual em um mundo globalizado. Parcerias estratégicas, 5(9), 145-156.

Candelin-Palmqvist, H., Sandberg, B., \& Mylly, U.-M. (2012). Intellectual property rights in innovation management research: a review. Technovation, 32(9-10), 502-512. doi: 10.1016/j.technovation.2012.01.005

Carvalho, S. M. P., Salles, S. L. M., Filho, \& Ferreira, C. (2005, outubro). Acesso das micros, pequenas e médias empresas ao sistema de propriedade intelectual no Brasil a partir do cruzamento de dados do IBGE e do INPI. Anais do Seminário de Gestión Tecnológica ALTEC, Salvador, Bahia, Brasil, 11.

Carvalho, S. M. P., Salles, S. L. M., Filho, \& Paulino, S. R. (2002). Propriedade intelectual e dinâmica de inovação na agricultura. Revista Brasileira de Inovação, 5(2), 315-340.

Chamas, C. I. (2003). Gerenciamento da proteção e exploração econômica da propriedade intelectual. Revista de Administração Pública, 37(5), 1055-1081.

Chaves, G. C., Oliveira, M. A., Hasenclaver, L., \& Melo, L. M. (2007). A evolução do sistema internacional de propriedade intelectual: proteção patentária para o setor farmacêutico e acesso a medicamentos. Cad. Saúde Pública, 23(2), 257-267. doi: 10.1590/S0102-311X2007000200002

Costa, P. R. da, Porto, G. S., \& Feldhaus, D. (2010). Gestão da cooperação universidade-empresa: o caso de uma multinacional brasileira. Revista de Administração Contemporânea, 14(1), 100121. Recuperado de http://www.anpad.org.br/periodicos/arq_pdf/a_1012.pdf. doi: 10.1590/S1415-65552010000100007

El-Bialy, N., \& Gouda, M. (2011). Can shari'a be a deterrent for intellectual property piracy in Islamic countries? The Journal of World Intellectual Property, 14(6), 441-466. doi: 10.1111/j.17471796.2011.00428.x

Gervais, D. J. (2009). Re-implementing the agreement on trade-related aspects of intellectual property rights to foster innovation. The Journal of World Intellectual Property, 12(5), 348-370. doi: 10.1111/j.1747-1796.2009.00379.x

Guerra, O. (2007). A nova petroquímica brasileira e o papel do estado. Bahia Análise e Dados, 17(2), 879-889.

Hanel, P. (2006). Intellectual property rights business management practices: a survey of the literature. Technovation, 26(8), 895-931. doi:10.1016/j.technovation.2005.12.001

Herscovici, A. (2007). Capital intangível e direitos de propriedade intelectual: uma análise institucionalista. Revista de economia política, 27(3), 394-412. doi: 10.1590/S010131572007000300005

Instituto Nacional da Propriedade Industrial. (n.d.a). Pesquisas. Bases de patentes, marcas. Portugal. Recuperado de http://www.inpi.pt/servicos/marcas_online.html

Instituto Nacional da Propriedade Industrial. (n.d.b). Pesquisas. Bases de patentes, marcas e desenhos industriais. Brasil, 2008. Recuperado de http://www.inpi.gov.br/menu-superior/pesquisas

Instituto Nacional de la Propiedad Industrial. (n.d.). Bases de datos. Argentina. Recuperado de http://www.inpi.gov.ar

Kretzer, J., \& Toyama, M. C. (2008). Inovações tecnológicas e mecanismos de proteção aos direitos autorais na indústria fonográfica. Revista Brasileira de Inovação, 7(1), 177-207. 
Lei $n^{\circ}$ 9.279, de 14 de maio de 1996. (1966). Regula os direitos e as obrigações relativos à propriedade industrial. Diário Oficial da República Federativa do Brasil. Recuperado de http://www.planalto.gov.br/ccivil_03/Leis/L9279.htm

Lerner, J. (2009). The empirical impact of intellectual property rights on innovation: puzzles and clues. American Economic Review: Papers \& Proceedings, 99(2), 343-348. doi: 10.1257/aer.99.2.343

Lima, C. M. de, \& Santini, R. M. (2008). Copyleft e licenças criativas de uso de informação na sociedade da informação. Ciência da Informação, 37(1), 121-128. doi: 10.1590/S010019652008000100011

Luna, F., \& Baessa, A. (2008). Impacto das marcas e das patentes no desempenho econômico das firmas. In J. A. de Negri, \& L. C. Kubota (Orgs.), Políticas de incentivo à inovação tecnológica no Brasil (pp. 463-501). Brasília: IPEA.

Mello, M. T. L. (2009). Propriedade intelectual e concorrência. Revista Brasileira de Inovação, 8(2), 371-402.

Oficina de Armonización Del Mercado Interior. (n.d.). CTM online - Servicio de consulta de marcas Básico. Recuperado de http://oami.europa.eu/CTMOnline/RequestManager/es_Result_NoReg

Pitkethly, R. H. (2001). Intellectual property strategy in Japanese and UK companies: patente licensing decisions and learning opportunities. Research Policy, 30(3), 425-442. doi: 10.016/S0048-7333(00)00084-6

Rosas, A. R., Froehner, J., \& Sbragia, R. (2007, setembro). O valor da proteção intelectual das inovações sob a perspectiva do empreendedor: um estudo de caso. Anais do Encontro Nacional da Associação Nacional de Pós-Graduação e Pesquisa em Administração, Rio de Janeiro, RJ, Brasil, 31.

Salles, S. L. M., Filho, Ferreira, C. R., \& Carvalho, S. M. P. (2006). Micros e pequenas e medias empresas acessam menos o sistema de patentes. Inovação Uniemp, 2(1), 22-22. Recuperado de http://inovacao.scielo.br/pdf/inov/v2n1/a13v2n1.pdf.

Santos, S., Guimarães, M. C. do, Melo, C. M. M., \& Sanchez, A., Filho (2006). Subsídios para avaliação da gestão pública: processo de construção de indicadores para avaliação da capacidade de gestão de organizações Sociais. Organização e Sociedade, 13(37), 109-124.

Sterckx, S., \& Cockbain, J. (2010, May). The patentability of computer programs in Europe: an improved interpretation of articles 52(2) and (3) of the European patent convention. The Journal of World Intellectual Property, 13(3), 366-402. doi: 10.1111/j.1747-1796.2009.00390.x

Teece, D. J. (2010). Business models, business strategy and innovation. Long Range Planning, 43(23), 172-194. doi: 10.1016/j.lrp.2009.07.003

Thumm, N. (2002). Europe's construction of a patent system for biotechnological inventions: an assessment of industry view. Technological Forecasting \& Social Change, 69(9), 917-928. doi: 10.1016/S0040-1625(01)00162-7

Tigre, P. B., \& Marques, F. S. (2009). Apropriação tecnológica na economia do conhecimento: inovação e propriedade intelectual de software na América Latina. Economia $e$ Sociedade, 18(3), 547-566. doi: 10.1590/S0104-06182009000300005

United States Patent and Trademarks Office. (n.d.). Patents and trademarks databases. EUA. Recuperado de http://www.uspto.gov/index.html

Vieira, A. C. P., Buainain. A. M., Dal Pozo, M. E., \& Vieira, P. A., Jr. (2010). Patenteamento da 
biotecnologia no setor agrícola no Brasil: uma análise crítica. Revista Brasileira de Inovação, 9(2), 323-354.

Yeung, M. T., \& Ker, W. A. (2011). Are geographical indications a wise strategy for developing country farmers? Greenfields, clawbacks and monopoly rents. The Journal of World Intellectual Property, 14(5), 353-367. doi: 10.1111/j.1747-1796.2011.00423.x 